\title{
The Effect of Annealing on Nanothick Indium Tin Oxide Transparent Conductive Films for Touch Sensors
}

\author{
Shih-Hao Chan, ${ }^{1}$ Meng-Chi Li, ${ }^{1}$ Hung-Sen Wei, ${ }^{1}$ \\ Sheng-Hui Chen, ${ }^{1}$ and Chien-Cheng Kuo ${ }^{1,2}$ \\ ${ }^{1}$ Department of Optics and Photonics and Thin Film Technology Center, National Central University, Chung-Li, Taiwan \\ ${ }^{2}$ Graduate Institute of Energy Engineering and Thin Film Technology Center, National Central University, Chung-Li, Taiwan \\ Correspondence should be addressed to Chien-Cheng Kuo; cckuo@ncu.edu.tw
}

Received 13 November 2014; Accepted 15 April 2015

Academic Editor: Ying-Lung Daniel Ho

Copyright (C) 2015 Shih-Hao Chan et al. This is an open access article distributed under the Creative Commons Attribution License, which permits unrestricted use, distribution, and reproduction in any medium, provided the original work is properly cited.

\begin{abstract}
This study aims to discuss the sheet resistance of ultrathin indium tin oxide (ITO) transparent conductive films during the postannealing treatment. The thickness of the ultrathin ITO films is $20 \mathrm{~nm}$. They are prepared on B270 glass substrates at room temperature by a direct-current pulsed magnetron sputtering system. Ultrathin ITO films with high sheet resistance are commonly used for touch panel applications. As the annealing temperature is increased, the structure of the ultrathin ITO film changes from amorphous to polycrystalline. The crystalline of ultrathin ITO films becomes stronger with an increase of annealing temperature, which further leads to the effect of enhanced Hall mobility. A postannealing treatment in an atmosphere can enhance the optical transmittance owing to the filling of oxygen vacancies, but the sheet resistance rises sharply. However, a higher annealing temperature, above $250^{\circ} \mathrm{C}$, results in a decrease in the sheet resistance of ultrathin ITO films, because more Sn ions become an effective dopant. An optimum sheet resistance of $336 \Omega /$ sqr was obtained for ultrathin ITO films at $400^{\circ} \mathrm{C}$ with an average optical transmittance of $86.8 \%$ for touch sensor applications.
\end{abstract}

\section{Introduction}

Transparent conducting oxide (TCO) thin films have drawn a great deal of attention in recent years and have been widely applied in various optoelectronic devices such as solar cells $[1,2]$, flat panel displays $[3,4]$, organic light emitting devices (OLED) [5-7], and a variety of handheld devices. Until now, tin-doped $\mathrm{In}_{2} \mathrm{O}_{3}$ (indium tin oxide, ITO) has been the most widely used of the TCO materials because of its low resistivity (less than $10^{-3} \Omega-\mathrm{cm}$ ) and good optical transmittance (more than $80 \%)$ in the visible region [8]. It is a degenerate $n$ type semiconductor with a wide energy band gap $(3.7 \mathrm{eV})$ and possesses the qualities of high mechanical hardness and chemical inertness [9].

In previous studies, ITO films have been deposited using a variety of techniques such as ion beam assisted deposition [10], direct current (dc) magnetron sputtering [11-14], and chemical vapor deposition [15]. A pulsed dc magnetron sputtering method is the most common technology for the deposition of ITO films, because it is an easy way to get high quality thin films [16]. Using these techniques, the properties of ITO films are dependent on the process parameters like the oxygen partial pressure, substrate temperature, and postannealing temperature and different substrates, such as glass and PET [17-20].

The thickness of ITO films from $40 \mathrm{~nm}$ to $2.58 \mu \mathrm{m}$ has been discussed in several studies. The results indicate that the electrical properties increase with increasing film thickness. However, the physical properties of the ITO film are notable when the thickness is less than $40 \mathrm{~nm}$. In conclusion, we can say that the thickness is the most significant factor influencing the crystallization [21-27]. The main conductive mechanism of ITO films can be attributed to Sn-doping and oxygen vacancies to provide more free electrons. However, the leading contributor to the carrier concentration in amorphous ITO films is indistinct [28]. A postannealing treatment is an attractive way to improve the crystalline and other properties of ITO films, because it is a simple and low-cost 
process. According to a related study, an ITO film of $200 \mathrm{~nm}$ thickness can be achieved by dc magnetron sputtering at room temperature. The lowest resistivity after being treated by rapid thermal annealing (RTA) at $600^{\circ} \mathrm{C}$ in a vacuum is about $1.6 \times 10^{-4} \Omega$-cm [29]. Gheidari et al. focused on the effect of the sputtering pressure and annealing temperature on the properties of ITO films. They found that the deposition rate decreases above 30 mTorr and the best conductivity and transmittance and larger grain size are achieved with an annealing temperature of $400^{\circ} \mathrm{C}[30]$.

Touch panels have become an important type of humancomputer interface in recent years, and the ITO is the most commonly used material for this component. It functions as a transparent conductivity oxide, which requires an optical transmittance of more than $85 \%$ and high sheet resistance between $300 \Omega /$ sqr and $500 \Omega / \operatorname{sqr}[31,32]$. However, in industrial practice ITO films are fabricated at room temperature with a postannealing treatment below $250^{\circ} \mathrm{C}$ in order to lower production cost. The fabrication cost can be reduced if ultrathin ITO films are used because less of the costly scarce rare element indium is used in its manufacture. However, the optical and electrical properties of ultrathin ITO films under an annealing temperature of $250^{\circ} \mathrm{C}$ are not well understood. This study focuses on postannealing treatment under the atmosphere for ultrathin ITO films deposited by dc pulsed magnetron sputtering at room temperature and what is needed to achieve high sheet resistance and high transmittance for touch sensor applications. The effect of the annealing temperature on the structure, electrical, and optical properties will be investigated, with a discussion of the properties of ultrathin ITO films.

\section{Experimental Details}

2.1. Film Preparation. ITO thin films were coated onto B270 substrates that were $25.4 \times 25.4 \mathrm{~mm}^{2}$ and $1 \mathrm{~mm}$ thick by a pulsed dc magnetron sputtering system at room temperature. Figure 1 shows a schematic representation of the pulsed DC magnetron sputtering system. This system consisted of a deposition chamber with two magnetron sputtering cathodes. There was a pulse generator with a frequency of $20 \mathrm{kHz}$ located between the dc power supply and the sputtering cathode. The pulse generator can help decrease the arcing and maintain stable plasma. The sputtering target was made of $\mathrm{In}_{2} \mathrm{O}_{3}$ mixed with $10 \mathrm{wt} . \% \mathrm{SnO}_{2}$ powder. An ITO target $75 \mathrm{~mm}$ in diameter was mounted on one cathode and set about $80 \mathrm{~mm}$ below the substrate.

The sputtering chamber was pumped down to a base pressure of less than $8 \times 10^{-6}$ Torr by a cryopump. During deposition, argon (Ar) was directly injected as the working gas and the working pressure was set to $2-3 \times 10^{-3}$ Torr. The major goal of this paper is to study the effects of different annealing temperatures on the optical and electrical properties of ultrathin ITO thin films. The ITO films were prepared with $100 \mathrm{~W}$ of sputtering power at room temperature for the same amount of time after which the films were annealed at various temperatures $\left(200-500^{\circ} \mathrm{C}\right)$ in air for $1 \mathrm{~h}$.

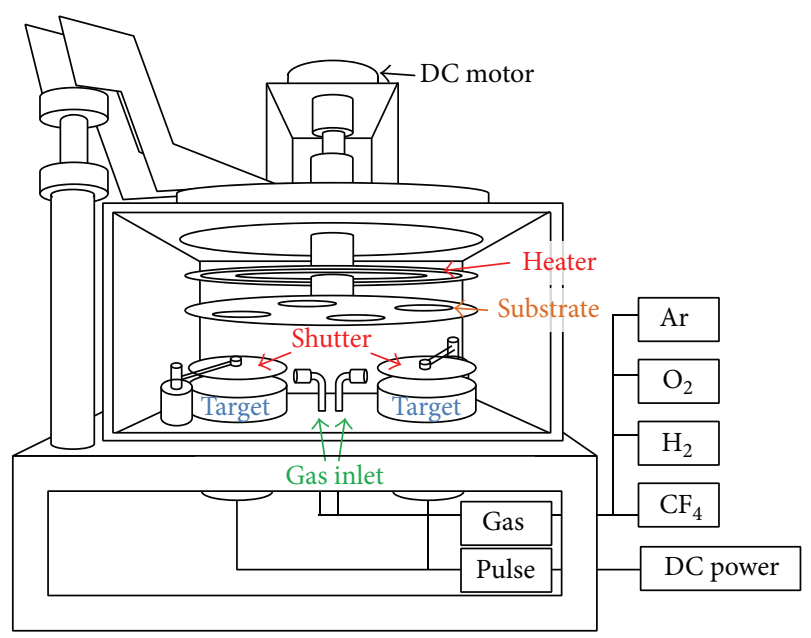

FIGURE 1: Schematic drawing of the experimental setup for pulsed dc magnetron sputtering.

2.2. Film Characterization. The thickness of all samples was about $20 \mathrm{~nm}$ as measured using a surface profiler (Dektak 8). The optical transmittance of thin films on B270 substrates was measured with a Hitachi U4100 spectrometer in the wavelength range from 300 to $700 \mathrm{~nm}$. The crystalline structure was then examined through X-ray diffraction (XRD). The resistivity, Hall mobility, and carrier concentration of the films were determined by Hall measurements (HEM-300) at room temperature.

\section{Results and Discussion}

Ultrathin $20 \mathrm{~nm}$ thick ITO films were deposited on B270 substrates at room temperature by a pulsed dc magnetron sputtering system. To compare the effect of annealing on the properties of ultrathin ITO films, the as-deposited films were annealed in air at various temperatures of 200, 250, 300, 350, 400,450 , and $500^{\circ} \mathrm{C}$. Figure 2 shows the carrier density, Hall mobility, and sheet resistance of the ultrathin ITO films at the various annealing temperatures, as obtained from the Hall Effect measurements carried out at room temperature. The electrical properties depend on the postannealing treatment. The crystallite size in the ITO films becomes larger as the annealing temperature increases, resulting in a decrease in boundary scattering and increase of the carrier lifetime [30]. However, the sheet resistance of the ultrathin ITO films increases with an increased annealing temperature, reaching a maximum value of $1075 \Omega / \mathrm{sqr}$ at an annealing temperature of $250^{\circ} \mathrm{C}$. After this, the sheet resistance decreases with increasing temperature. This is an interesting result which differs from the results for ITO films of more than $40 \mathrm{~nm}$. When as-deposited films are annealed in air, the free oxygen easily fills up oxygen vacancies in the lattice of the $\operatorname{In}_{2} \mathrm{O}_{3}$ structure, because of the ultrathin thickness of the ITO films. This reaction will decrease the oxygen vacancies and carrier concentration, which leads to an increase in the sheet resistance of the ultrathin ITO films. This also contributes to oxidation, resulting in an increase of the transmittance, as 


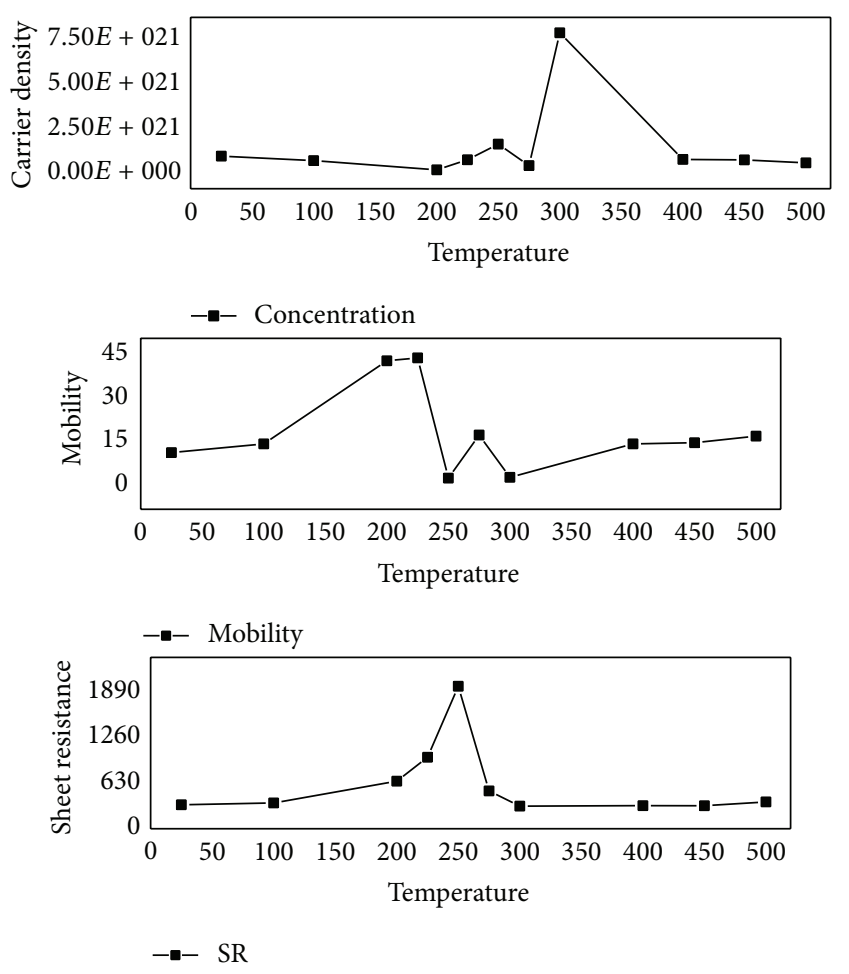

FIgURE 2: Comparison of the electrical properties of ultrathin ITO films as a function of the annealing temperature.

shown in Figure 3. Figure 3 shows the transmittance spectra of ultrathin ITO films before and after annealing at different temperatures. The average transmittance in the visible region $(400-700 \mathrm{~nm})$ before annealing is $83.84 \%$, but this increases to over $85 \%$ after annealing at over $250^{\circ} \mathrm{C}$. The inset to the figure shows an obvious increase in the transmittance with the increase in annealing temperature. This result corresponds with the aforementioned Hall measurements.

In addition to oxidation to fill up the oxygen vacancies, there is another possibility for the improvement of transmittance in ITO films which is also attributed to good crystallinity. However, the ultrathin ITO films do not easily crystallize at low annealing temperatures. The crystallization of the ultrathin ITO films is strongly dependent on the higher annealing temperature and the phase change from amorphous to crystalline during the annealing treatment, as shown in Figure 4. The transmittance of the crystalline structure is higher than that of the amorphous structure and this implies that the transmittance in the visible light range of ultrathin ITO films is closely related to the film structure. The grain-boundary scattering mechanism in polycrystalline ITO films has been discussed in a previous report [30]. The crystalline structure of the films can be improved and the crystallite size increased after annealing, which can decrease the scattering of incident light by decreasing the number of grain-boundaries and enhancing the transmittance. The crystallinity of ultrathin ITO films is higher, which further results in the effect of enhanced Hall mobility.

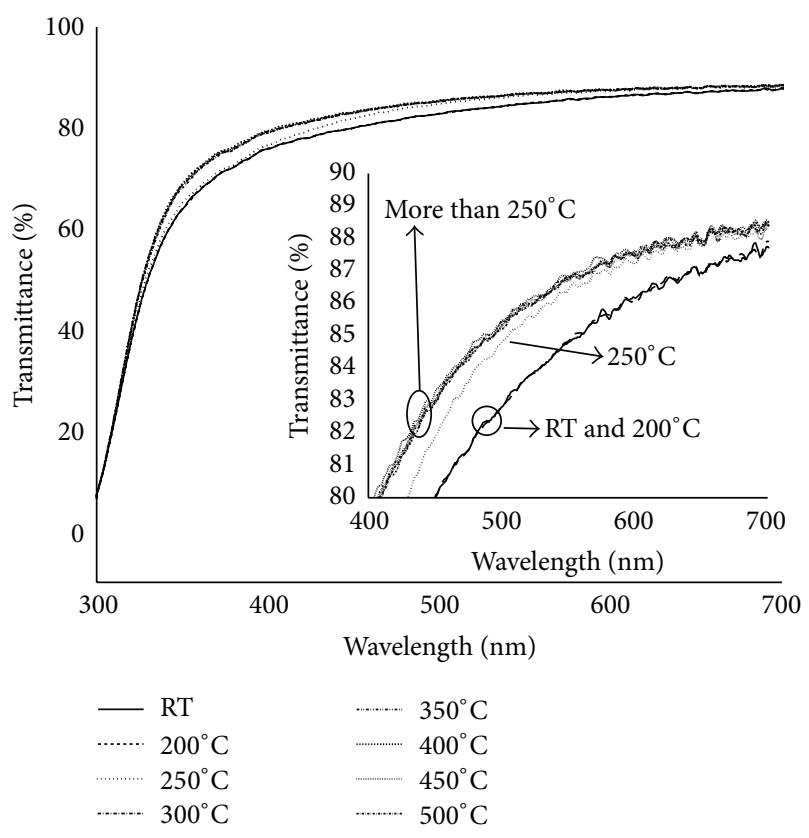

FIGURE 3: Optical transmittance of ultrathin ITO films during annealing treatment with various annealing temperatures.

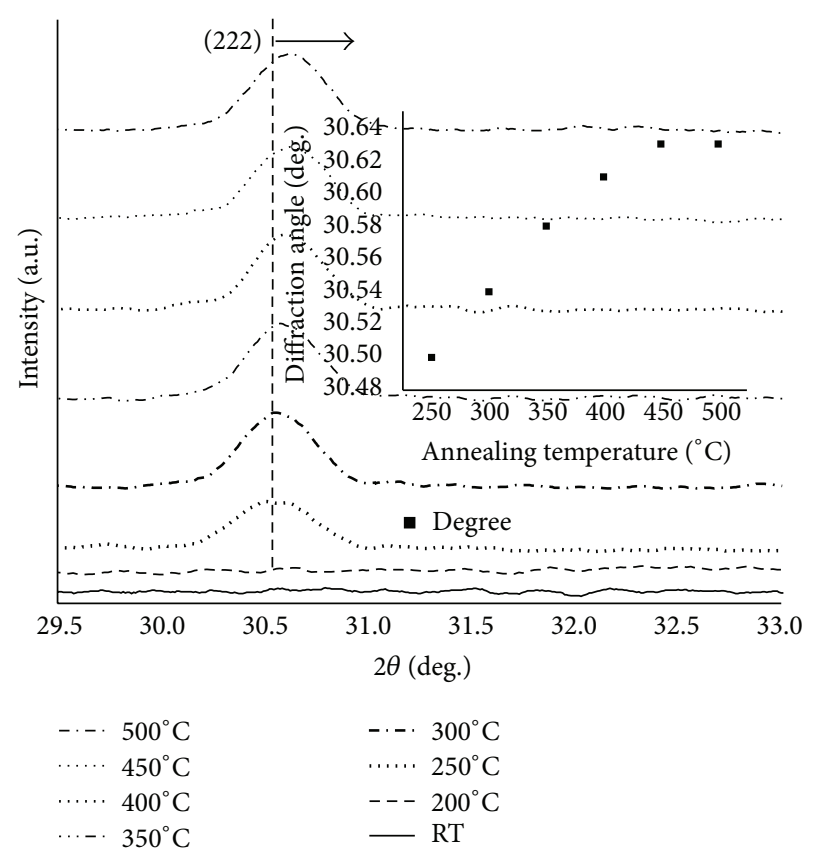

FIGURE 4: X-ray diffraction peaks and diffraction angles of ultrathin ITO films during annealing treatment with various annealing temperatures.

The results discussed above seem to contradict the sheet resistance of the Hall measurement when the annealing temperature is more than $250^{\circ} \mathrm{C}$. This is a point worthy of discussion. A higher annealing temperature leads to a decrease in the sheet resistance of ultrathin ITO films. This is due to the fact that the annealing treatment rearranges 
the structure of the ITO films, causing more Sn ions to become an effective dopant. This is demonstrated by the XRD measurements. It can be seen in the inset to Figure 4 that the (222) peak intensity of the ITO films becomes higher with the increase of annealing temperature. Consequently, there is a decrease in the sheet resistance because of the replacement of the $\mathrm{In}^{3+}$ by $\mathrm{Sn}^{2+}$ when the annealing temperature exceeds $250^{\circ} \mathrm{C}$. According to Bragg's law, the Bragg angle $(\theta)$ increases due to a decrease in the $d$ spacing. The length of the $d$ spacing is expected to be shorter if the In ions are replaced by $\mathrm{Sn}$ ions, due to the smaller ionic radius of $\mathrm{Sn}$ (the ionic radii of $\mathrm{In}^{3+}$ and $\mathrm{Sn}^{4+}$ are 80 and $69 \mathrm{pm}$, resp.). This is also consistent with the results obtained for the electrical properties and the increase in carriers owing to the more effective dopant. Furthermore, the more effective dopant acts as a donor source to increase the mobility of ITO films. In this study, the best conditions for ultrathin ITO films for touch sensor applications offer a sheet resistance of $336 \Omega$ /sqr and an optical transmittance of $86.8 \%$ in the visible region when the annealing temperature is $400^{\circ} \mathrm{C}$.

\section{Conclusion}

Ultrathin ITO films were prepared on B270 glass substrates at room temperature by the dc pulsed magnetron sputtering method. The effect of the annealing temperature on ultrathin ITO films was investigated. As the annealing temperature is increased, the structure of the ultrathin ITO film changes from amorphous to polycrystalline. The postannealing treatment in the atmosphere can enhance the optical transmittance owing to a filling up of the oxygen vacancies, but there is also a sharp rise in the sheet resistance. A higher annealing temperature of above $250^{\circ} \mathrm{C}$ results in a decrease in the sheet resistance of the ultrathin ITO films because of more $S n$ ions, to become an effective dopant. The crystallinity of ultrathin ITO films becomes higher with an increase of annealing temperature, which further leads to the effect of enhanced Hall mobility. In terms of the sheet resistance and transmittance, an annealing temperature of $400^{\circ} \mathrm{C}$ is the best for our ultrathin ITO samples. A suitable sheet resistance of $336 \Omega /$ sqr was obtained for ultrathin ITO films at $400^{\circ} \mathrm{C}$ with an average optical transmittance of $86.8 \%$ making it suitable for applications in touch sensors.

\section{Conflict of Interests}

The authors declare that there is no conflict of interests regarding the publication of this paper.

\section{Acknowledgment}

The authors would like to thank the National Science Council of Taiwan for financial support of this research under Contracts nos. NSC 102-2633-E-008-001, NSC 103-2623-E-008001-ET, and MOST 103-2221-E-008-101-MY2.

\section{References}

[1] A. Yamada, B. Sang, and M. Konagai, "Atomic layer deposition of $\mathrm{ZnO}$ transparent conducting oxides," Applied Surface Science, vol. 112, pp. 216-222, 1997.

[2] K. Matsubara, P. Fons, K. Iwata et al., " $\mathrm{ZnO}$ transparent conducting films deposited by pulsed laser deposition for solar cell applications," Thin Solid Films, vol. 431-432, pp. 369-372, 2003.

[3] M. Katayama, “TFT-LCD technology," Thin Solid Films, vol. 341, no. 1, pp. 140-147, 1999.

[4] J. F. Wager, “Transparent electronics," Science, vol. 300, no. 5623, pp. 1245-1246, 2003.

[5] V. Bulović, P. Tian, P. E. Burrows, M. R. Gokhale, S. R. Forrest, and M. E. Thompson, "A surface-emitting vacuum-deposited organic light emitting device," Applied Physics Letters, vol. 70, no. 22, pp. 2954-2956, 1997.

[6] H. Kim, C. M. Gilmore, J. S. Horwitz et al., "Transparent conducting aluminum-doped zinc oxide thin films for organic light-emitting devices," Applied Physics Letters, vol. 76, no. 3, pp. 259-261, 2000.

[7] M. Ikai, S. Tokito, Y. Sakamoto, T. Suzuki, and Y. Taga, "Highly efficient phosphorescence from organic light-emitting devices with an exciton-block layer," Applied Physics Letters, vol. 79, no. 2, pp. 156-158, 2001.

[8] H. L. Hartnagel, A. L. Dawar, A. K. Jain, and C. Jagadish, Semiconducting Transparent Thin Films, Institute of Physics, Philadelphia, Pa, USA, 1995.

[9] A. El-Hichou, A. Kachouane, J. L. Bubendorff et al., "Effect of substrate temperature on electrical, structural, optical and cathodoluminescent properties of $\operatorname{In}_{2} \mathrm{O}_{3}$-Sn thin films prepared by spray pyrolysis," Thin Solid Films, vol. 458, no. 1-2, pp. 263$268,2004$.

[10] J. L. Grieser, "Comparison of ITO films produced by standard D.C. sputtering and ion beam assisted sputtering," in Proceedings of the 38th Annual Technical Conference, pp. 155162, Society of Vacuum Coaters, 1995.

[11] M. Bender, W. Seelig, C. Daube, H. Frankenberger, B. Ocker, and J. Stollenwerk, "Dependence of oxygen flow on optical and electrical properties of DC-magnetron sputtered ITO films," Thin Solid Films, vol. 326, no. 1-2, pp. 72-77, 1998.

[12] C. G. Choi, K. No, W.-J. Lee et al., "Effects of oxygen partial pressure on the microstructure and electrical properties of indium tin oxide film prepared by d.c. magnetron sputtering," Thin Solid Films, vol. 258, no. 1-2, pp. 274-278, 1995.

[13] A. N. H. Al-Ajili and S. C. Bayliss, "A study of the optical, electrical and structural properties of reactively sputtered $\mathrm{InO}_{x}$ and ITO $_{x}$ thin films," Thin Solid Films, vol. 305, no. 1-2, pp. 116123, 1997.

[14] S. K. Choi and J. I. Lee, "Effect of film density on electrical properties of indium tin oxide films deposited by dc magnetron reactive sputtering," Journal of Vacuum Science \& Technology A, vol. 19, p. 2043, 2001.

[15] K. Maki, N. Komiya, and A. Suzuki, "Fabrication of thin films of ITO by aerosol CVD," Thin Solid Films, vol. 445, no. 2, pp. 224-228, 2003.

[16] W. M. Gnehr, U. Hartung, and T. Kopte, "Society of vacuum coaters," in Proceedings of the 48th Annual Technical Conference, p. 312, 2005.

[17] Y.-C. Park, Y.-S. Kim, H.-K. Seo, S. G. Ansari, and H.-S. Shin, "ITO thin films deposited at different oxygen flow rates on 
Si(100) using the PEMOCVD method," Surface and Coatings Technology, vol. 161, no. 1, pp. 62-69, 2002.

[18] C. Guillén and J. Herrero, "Structure, optical, and electrical properties of indium tin oxide thin films prepared by sputtering at room temperature and annealed in air or nitrogen," Journal of Applied Physics, vol. 101, Article ID 073514, 2007.

[19] L. Kerkache, A. Layadi, and A. Mosser, "Effect of oxygen partial pressure on the structural and optical properties of dc sputtered ITO thin films," Journal of Alloys and Compounds, vol. 485, no. 1-2, pp. 46-50, 2009.

[20] T. Katsuyama, K. Hirima, K. Ogawa, K.-I. Haraguchi, and M. Yazawa, "Optical properties of GaAs nano-whiskers," Japanese Journal of Applied Physics, vol. 34, supplement 34-1, p. 224, 1995.

[21] S. Sivaranjani, V. Malathy, J. J. Prince et al., “Thickness dependence of structural, electrical and optical properties of sputter deposited indium tin oxide films," Advanced Science Letters, vol. 3, no. 4, pp. 434-441, 2010.

[22] K. J. Kumar, N. R. C. Raju, and A. Subrahmanyam, "Rapid thermal annealing of ITO films," Applied Surface Science, vol. 257, pp. 7061-7064, 2011.

[23] K. S. Shamala, L. C. S. Murthy, and K. N. Rao, "Studies on tin oxide films prepared by electron beam evaporation and spray pyrolysis methods," Bulletin of Materials Science, vol. 27, no. 3, pp. 295-301, 2004.

[24] Z. Qiao, R. Latz, and D. Mergel, "Thickness dependence of $\mathrm{In}_{2} \mathrm{O}_{3}$ :Sn film growth," Thin Solid Films, vol. 466, no. 1-2, pp. 250-258, 2004.

[25] M.-Z. Gao, R. Job, D.-S. Xue, and W. R. Fahrner, "Thickness dependence of resistivity and optical reflectance of ITO films," Chinese Physics Letters, vol. 25, no. 4, pp. 1380-1383, 2008.

[26] D. H. Kim, M. R. Park, H. J. Lee, and G. H. Lee, “Thickness dependence of electrical properties of ITO film deposited on a plastic substrate by RF magnetron sputtering," Applied Surface Science, vol. 253, pp. 409-411, 2006.

[27] H. Kim, J. S. Horwitz, G. Kushto et al., "Effect of film thickness on the properties of indium tin oxide thin films," Journal of Applied Physics, vol. 88, no. 10, pp. 6021-6025, 2000.

[28] H. Morikawa and M. Fujita, "Crystallization and electrical property change on the annealing of amorphous indium-oxide and indium-tin-oxide thin films," Thin Solid Films, vol. 359, no. 1, pp. 61-67, 2000.

[29] S. Song, T. Yang, J. Liu, Y. Xin, Y. Li, and S. Han, "Rapid thermal annealing of ITO films," Applied Surface Science, vol. 257, no. 16, pp. 7061-7064, 2011.

[30] A. M. Gheidari, F. Behafarid, G. Kavei, and M. Kazemzad, "Effect of sputtering pressure and annealing temperature on the properties of indium tin oxide thin films," Materials Science and Engineering B: Solid-State Materials for Advanced Technology, vol. 136, no. 1, pp. 37-40, 2007.

[31] M. H. Ahn, E.-S. Cho, and S. J. Kwon, "Effect of the duty ratio on the indium tin oxide (ITO) film deposited by in-line pulsed DC magnetron sputtering method for resistive touch panel," Applied Surface Science, vol. 258, no. 3, pp. 1242-1248, 2011.

[32] S.-F. Tseng, W.-T. Hsiao, K.-C. Huang, D. Chiang, M.-F. Chen, and C.-P. Chou, "Laser scribing of indium tin oxide (ITO) thin films deposited on various substrates for touch panels," Applied Surface Science, vol. 257, no. 5, pp. 1487-1494, 2010. 

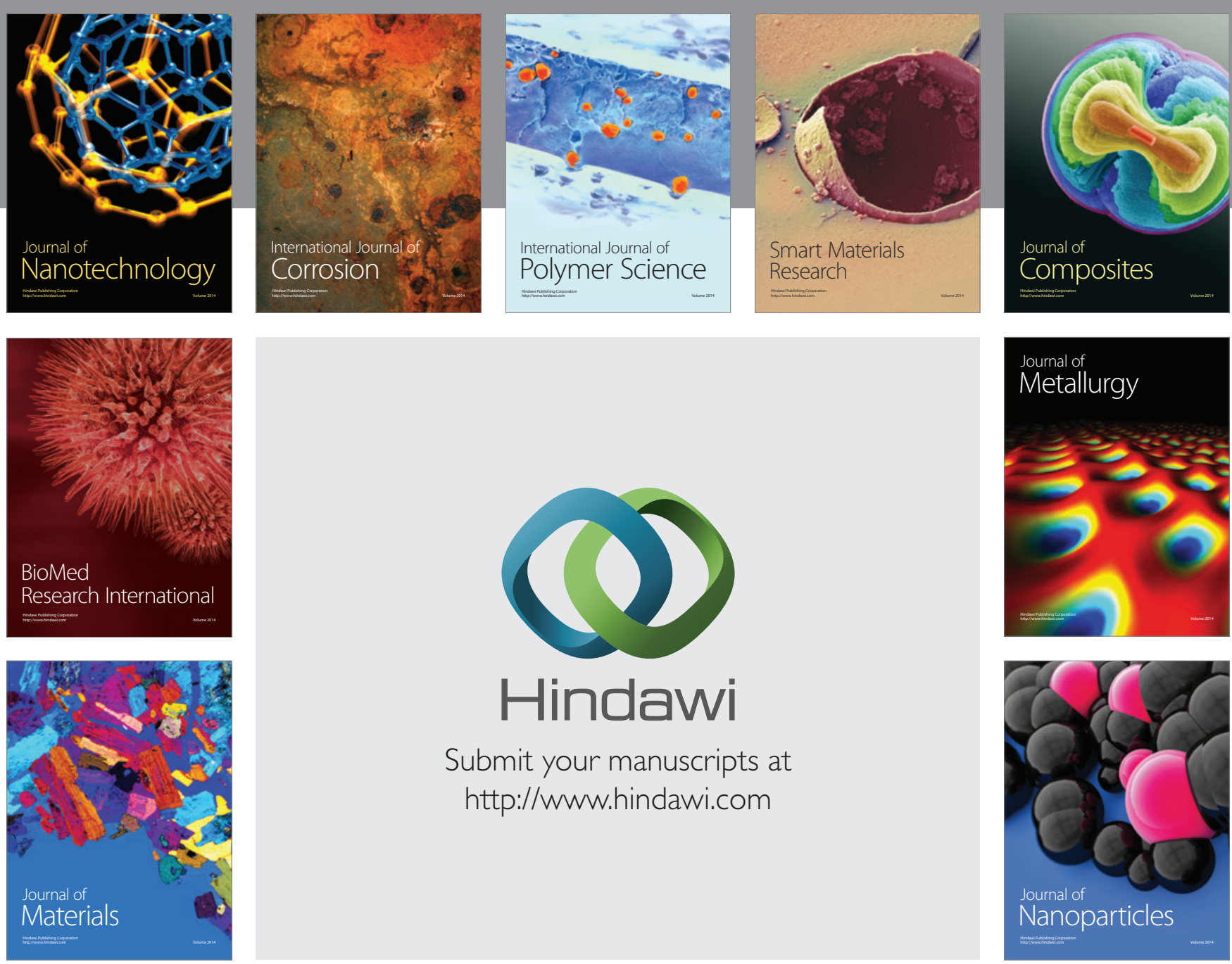

Submit your manuscripts at http://www.hindawi.com
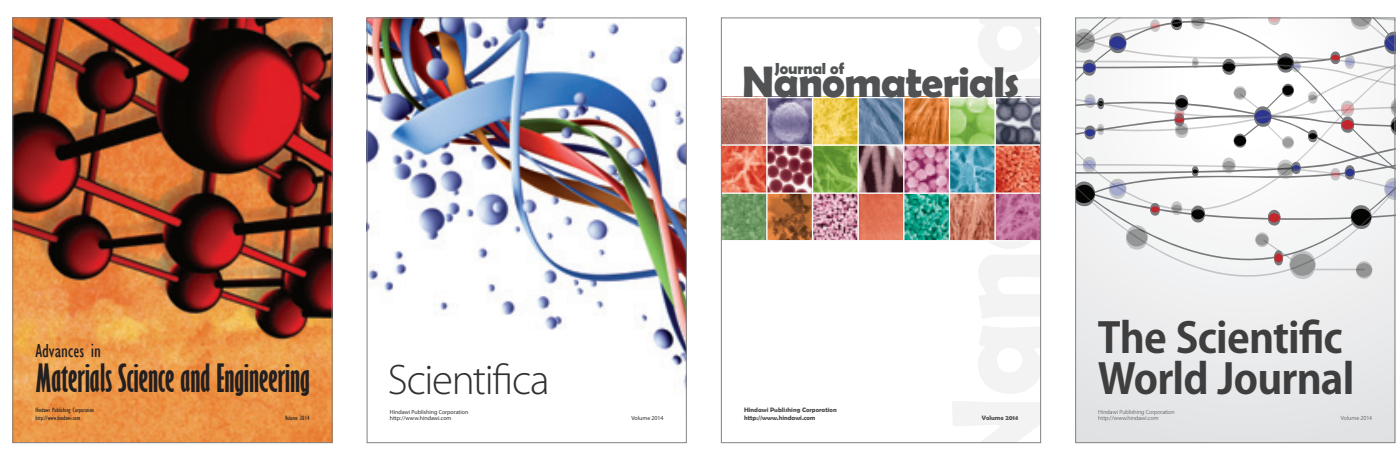

\section{The Scientific World Journal}
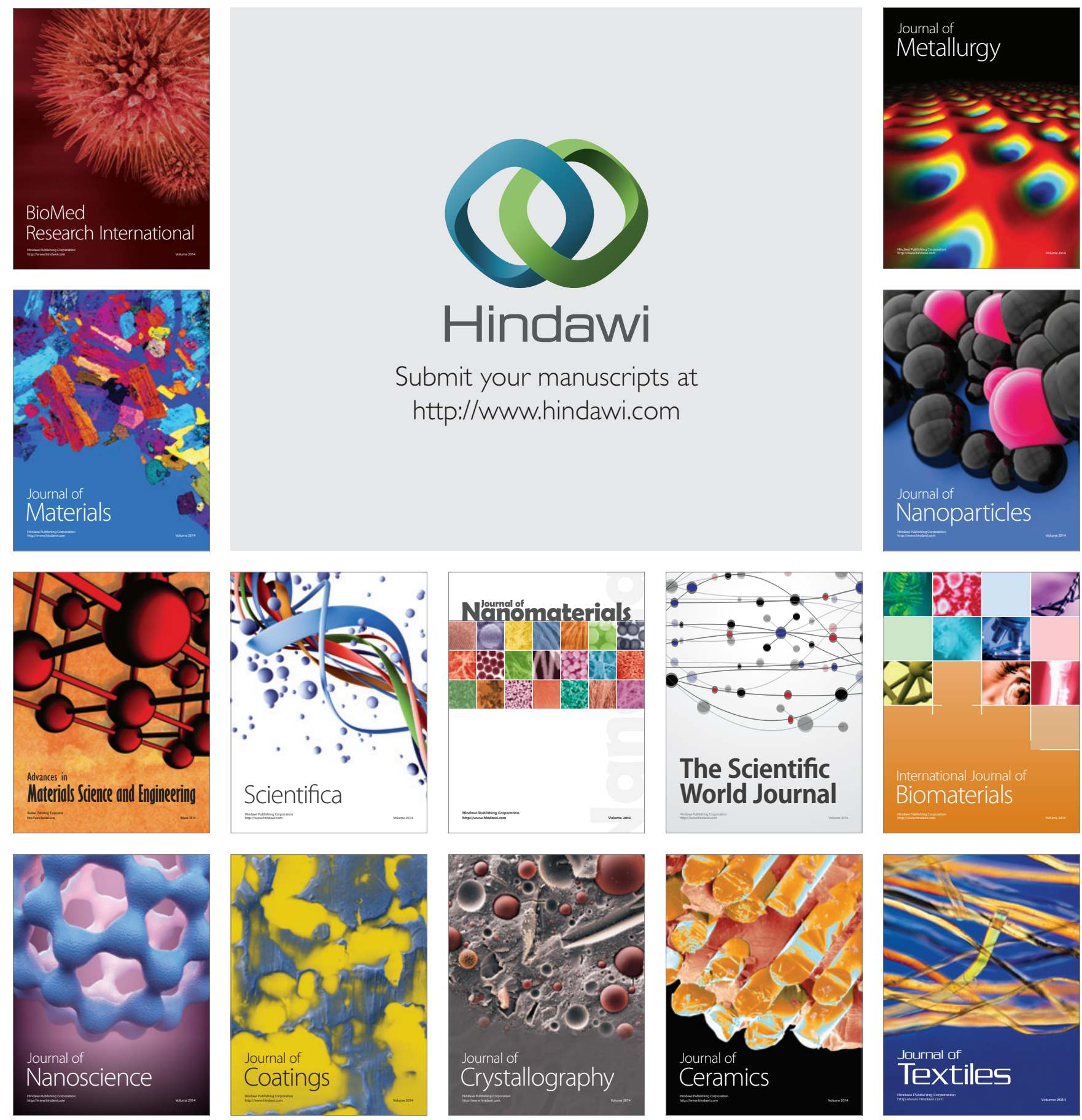